\title{
The Girl in the Spotlight: Vermeer at work, his materials and techniques in Girl with a Pearl Earring
}

\author{
Abbie Vandivere ${ }^{1 *}\left(\mathbb{D}\right.$, Jørgen Wadum ${ }^{2}$ and Emilien Leonhardt ${ }^{3}$
}

\begin{abstract}
The 2018 technical examination project The Girl in the Spotlight aimed to characterise the materials and techniques that Johannes Vermeer used to paint Girl with a Pearl Earring (c. 1665, Mauritshuis). Five research questions guided the micro- and macro-scale analyses: What can we find out about layers beneath the surface? What steps did Vermeer take to create the painting? Which materials did Vermeer use and where did they come from? Which techniques did Vermeer use to create subtle optical effects? What did the painting look like originally, and how has it changed? This paper concludes the special issue of Heritage Science by summarising the results and putting them in an art-historical and materials history context. Non-invasive macroscopic imaging methods were used to examine the Girl, in conjunction with the (re)analysis of microscopic samples. Here, Vermeer's painting techniques are revealed using microphotographs made using a high-resolution 3D digital microscope at 140x magnification (1.1 $\mu \mathrm{m} /$ pixel).
\end{abstract}

Keywords: Seventeenth century, Vermeer, Netherlands, Painting technique, Technical examination, Materials, Pigments

\section{Introduction}

In 2018, Johannes Vermeer's masterpiece Girl with a Pearl Earring (c. 1665, Mauritshuis, Fig. 1) was examined in front of the public at the Mauritshuis using state-ofthe-art imaging techniques, as part of the research project The Girl in the Spotlight [1]. Micro-samples taken during the 1994 restoration treatment were reanalysed, and four new samples were collected and analysed [2]. This concluding paper presents and summarises some findings of the micro- and macro-scale examination techniques applied to the painting. Results about specific areas-the layers beneath the surface [3], the pigment distribution [4], the Girl's skin [5], her blue headscarf [6], and the background [7]-are described in detail in the preceding articles in this special issue of Heritage Science. Investigating the painting's topography [8]

\footnotetext{
*Correspondence: a.vandivere@mauritshuis.nl

${ }^{1}$ Conservation Department, Mauritshuis, Plein 29, 2511 CS The Hague, the Netherlands

Full list of author information is available at the end of the article
}

and degradation products [9] are relevant to understand how the painting has changed over time. This concluding paper seeks to answer five research questions posed at the outset of the project, and considers them within a (technical) art historical context.

\section{What can we find out about layers beneath the surface?}

Beneath the painted surface of Girl with a Pearl Earring are the canvas, ground and underlayer(s) of paint [3]. The preparatory steps-stretching and sizing the canvas, applying the grey ground, and producing pigments from raw materials - were probably not done by Vermeer himself [3]. Archival research carried out in the 1990s found that a range of artists' materials, including pre-primed canvases, were available in the Netherlands in Vermeer's time, and that some materials could have been purchased locally in Delft $[10,11]$.

As part of the Girl in the Spotlight project, microscopic paint samples collected during the 1994 restoration treatment were re-examined, and four new samples were taken from underrepresented areas [1, 2]. Analysing

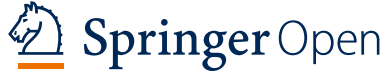

(c) The Author(s) 2020. This article is licensed under a Creative Commons Attribution 4.0 International License, which permits use, sharing adaptation, distribution and reproduction in any medium or format, as long as you give appropriate credit to the original author(s) and the source, provide a link to the Creative Commons licence, and indicate if changes were made. The images or other third party material in this article are included in the article's Creative Commons licence, unless indicated otherwise in a credit line to the material. If material is not included in the article's Creative Commons licence and your intended use is not permitted by statutory regulation or exceeds the permitted use, you will need to obtain permission directly from the copyright holder. To view a copy of this licence, visit http://creativeco mmons.org/licenses/by/4.0/. The Creative Commons Public Domain Dedication waiver (http://creativecommons.org/publicdomain/ zero/1.0/) applies to the data made available in this article, unless otherwise stated in a credit line to the data. 


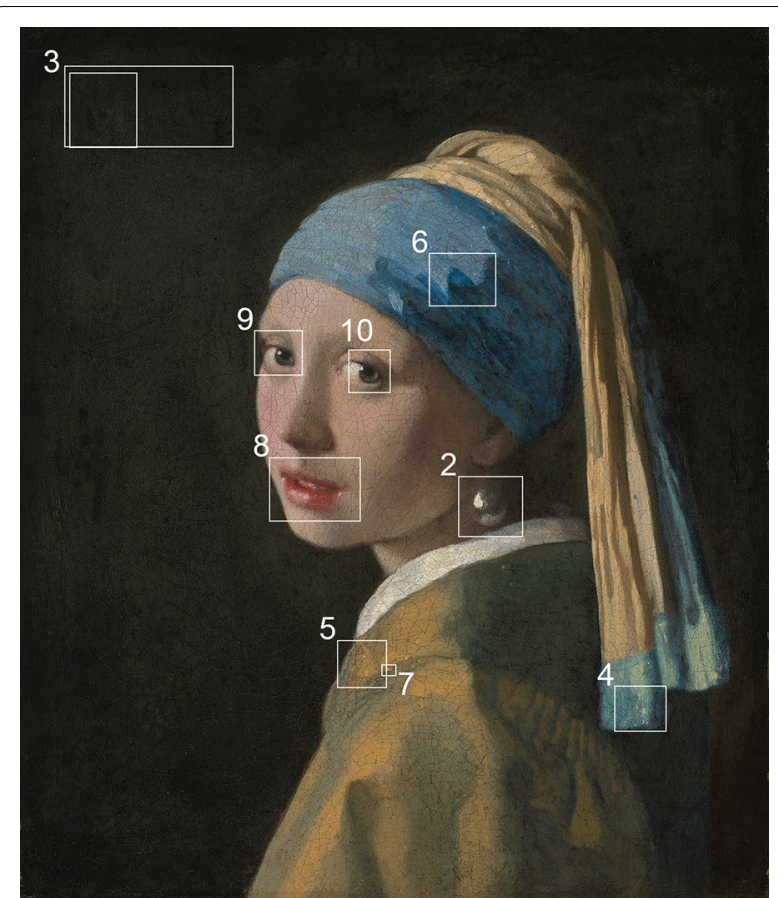

Fig. 1 Johannes Vermeer, Girl with a Pearl Earring, c. 1665. MH670, Mauritshuis, The Hague. Visible light photograph: René Gerritsen Art \& Research Photography. Locations of Figs. 2-10 are labelled with boxes. For an online zoomable stitched 3D digital microphotograph $(\times 35,4.4 \mu \mathrm{m} /$ pixel), with details $(\times 140,1.1 \mu \mathrm{m} /$ pixel): www.micro -pano.com/pearl

samples mounted as cross-sections revealed the stratigraphy, thickness, and composition of these layers beneath the surface (Table 1). Light microscopy of cross-sections showed a rather simple buildup in most colour areas: usually one or two underlayers, and one upper paint layer. The interface between them is a distinct line, indicating that Vermeer left underlayers to dry before applying the upper layers.

To complement the visualisation of the stratigraphy gained from the cross-sections, non-invasive imaging technologies were used to identify and map materials in sub-surface layers, without having to make physical contact with the painting [1]. The underlayers that contain carbon could be detected using multispectral infrared reflectography (MS-IRR). A combination of MS-IRR and $3 \mathrm{D}$ digital microscopy revealed that Vermeer painted fine black outlines to delineate the perimeter of figure against the dark background [3].

In the clothing, the light grey ground provided a neutral base tone, on top of which Vermeer painted in monochrome shades of brown and black to establish the areas of light and shadow within the composition [3]. In the Girl's jacket-especially her shoulder-he applied the underlayer with swift broad brushstrokes [3]. He varied its colour: a light brown on the left (lit) side of the jacket, and a darker brown-black on the right (shadow). At a later stage, he applied the upper layers of paint on top, leaving the dark underlayer in the shadow somewhat visible through the thin paint. Vermeer applied the blue paint layers in the Girl's headscarf on top of the grey ground on the left side, and on top of a black underlayer on the right side [6]. Beneath the Girl's face, the underlayers vary in colour: a light cream on the left side that faces the light, and red-brown in the shadow on the right [5]. The dark background has a black underlayer, beneath a green glaze [7].

For more information about the samples: [1, Additional file 1: Appendix S1]. For sample locations: [1, Fig. 3].

Complementary information about pigment composition and distribution was obtained by examining the painting using imaging methods, including: fluorescence and reflectance imaging spectroscopy, macroscopic X-ray fluorescence imaging, and X-ray powder diffraction imaging.

\section{What steps did Vermeer take to create the painting?}

It appears that Vermeer applied the underlayers rather swiftly, with broad brushstrokes in most areas. He would have waited until the underlayers were completely dry; however, the black underlayer in the background would have taken longer to dry than the brown underlayer beneath the figure. Vermeer was a 'slow' painter: not in his brushwork, but in his patient and deliberate application of each stage in the painting process. When applying the upper paint layers, Vermeer worked swiftly but precisely; his surehandedness and accuracy are evident in the virtuosic way he painted elements like the pearl earring. He made some changes (pentimenti) during the painting process, including: shifting the ear upwards, adjusting the line between her cheek and the headscarf, and softening the contour at the back of her neck [3].

The monochrome underlayers, now mostly hidden beneath the surface, show that Vermeer seems to have had the strong lighting in mind from the outset. Since he had already laid in the modelling of light and shade, he only needed to apply one or two paint layers on top to achieve the desired effects. In the upper layers, he appears to have worked on each colour area separately. Where the colours overlap with each other it is possible to determine which he painted first. However, in other areas-like between the Girl's face and the backgroundthere is a 'gap' between adjacent colours, which makes it difficult to know the order of painting.

Based on examination under a stereomicroscope and 3D digital microscope, it seems that Vermeer worked rather systematically from background to foreground. The first paint layer that he applied on top of 
Table 1 Composition and layer stratigraphy in different areas of Girl with a Pearl Earring, identified from the (re)analysis of samples, 2017-19

\begin{tabular}{|c|c|c|c|}
\hline Area of painting/Reference & $\begin{array}{l}\text { Description of layers (on top } \\
\text { of ground), and the pigments they } \\
\text { contain }\end{array}$ & Sample numbers & $\begin{array}{l}\text { Analytical methods used to examine } \\
\text { samples, 2017-19 } \\
\text { Not all samples were analysed } \\
\text { with every method }\end{array}$ \\
\hline \multirow[t]{2}{*}{ Background $[3,4,7]$} & $\begin{array}{l}\text { Green glaze: indigo, weld, chalk (sub- } \\
\text { strate), lead white, red earth, dispersed } \\
\text { copper (presumably as drier) }\end{array}$ & 5(B), 19(A), 21(A), 26(B), 34(B) & $\begin{array}{l}\text { FIB-STEM, FTIR-ATR, LM, SEM-EDX, THM-Py- } \\
\text { GC/MS, UHPLC-PDA-FLR }\end{array}$ \\
\hline & $\begin{array}{l}\text { Black underlayer: mostly charcoal, rela- } \\
\text { tively small amounts of: gypsum, chalk, } \\
\text { earth pigment, possibly alum (associ- } \\
\text { ated with a lake pigment) }\end{array}$ & & \\
\hline \multirow[t]{2}{*}{ Skin, highlight [3-5] } & $\begin{array}{l}\text { Pink layer: Lead white, vermilion, red lake, } \\
\text { yellow earth, ultramarine }\end{array}$ & $40(A)$ & $\begin{array}{l}\text { FIB-STEM, FTIR-ATR, LIA, LM, SEM-EDX, } \\
\text { } \text { } \text { XXRPD, }\end{array}$ \\
\hline & $\begin{array}{l}\text { Yellowish-cream underlayers: lead white, } \\
\text { yellow earth, occasional particles of red } \\
\text { lake, quartz, chalk, small carbon-based } \\
\text { black particles }\end{array}$ & & \\
\hline \multirow[t]{3}{*}{ Skin, shadow [3-5] } & $\begin{array}{l}\text { Pinkish-brown layer: lead white, yellow } \\
\text { earth, a little red lake, bone black }\end{array}$ & $39(A)$ & $\begin{array}{l}\text { FIB-STEM, FTIR-ATR, LIA, LM, SEM-EDX, } \\
\text { } \text { MXRPD }\end{array}$ \\
\hline & $\begin{array}{l}\text { Red-brown layer: red lake, bone black, } \\
\text { yellow earth, vermilion }\end{array}$ & & \\
\hline & $\begin{array}{l}\text { Dark brown underlayer: dark brown matrix } \\
\text { with red lake, bone black }\end{array}$ & & \\
\hline \multirow[t]{2}{*}{ Blue headscarf, shadow $[3,4,6]$} & $\begin{array}{l}\text { Blue layer: ultramarine, lead white, very } \\
\text { little red lake, chalk (probably substrate } \\
\text { of yellow lake, now faded) }\end{array}$ & $23(A), 41(A), 42(A)$ & $\begin{array}{l}\text { FTIR-ATR, LM, SEM-EDX, UHPLC-PDA-FLR, } \\
\quad \mu \text { XANES }\end{array}$ \\
\hline & Black underlayer: charcoal & & \\
\hline \multirow[t]{2}{*}{ Yellow'tail' of headscarf $[3,4]$} & $\begin{array}{l}\text { Yellow layer: lead-tin yellow, yellow earth, } \\
\text { lead white, possibly substrate of yellow } \\
\text { lake }\end{array}$ & $28(A)$ & FTIR-ATR, LM, SEM-EDX \\
\hline & $\begin{array}{l}\text { Dark underlayer: Carbon-based black } \\
\text { pigment (might not underlie the whole } \\
\text { area) }\end{array}$ & & \\
\hline \multirow[t]{2}{*}{ Yellow jacket, highlight $[3,4]$} & $\begin{array}{l}\text { Yellow layer: yellow earth, lead white, } \\
\text { ultramarine }\end{array}$ & $25(A)$ & FTIR-ATR, LM, SEM-EDX \\
\hline & $\begin{array}{l}\text { Brown underlayer: earth pigments includ- } \\
\text { ing yellow earth, lead white, charcoal }\end{array}$ & & \\
\hline \multirow[t]{2}{*}{ Yellow jacket, shadow $[3,4]$} & $\begin{array}{l}\text { Brown layer: yellow earth, ultramarine, red } \\
\text { lake, black }\end{array}$ & $7(B), 10(B), 11(A), 14(B), 22(A)$ & $\begin{array}{l}\text { FIB-STEM, FTIR-ATR, LM, SEM-EDX, SIMS, } \\
\text { UHPLC-PDA-FLR, } \mu \text { XRPD }\end{array}$ \\
\hline & $\begin{array}{l}\text { Dark brown underlayer: earth pigments, } \\
\text { red lake, charcoal, bone black }\end{array}$ & & \\
\hline
\end{tabular}

the underlayer(s) appears to be the greenish glaze in the background [7]. Her skin-which itself was modelled in several phases-was next, followed by the upper layers of her clothing. Her yellow jacket preceded the white collar. Her headscarf was painted fairly late in the process: first the light blue of the headscarf, then the yellows and browns in the 'tail', then returning with a darker blue. In the final stages of the painting process, Vermeer applied some translucent glazes, and painted small highlights and details (see question 4 below) [4-6]. The pearl earring sits on the surface of the paint: a scumble creates the soft counter-reflection from her white shirt, and a teardropshaped highlight was applied with thick impasto (Fig. 2).
Both were painted on top of the completed skin tone of the Girl's neck [4]. Presumably Vermeer applied his signature at the very end; the 3D microphotograph suggests that it sits on top of the upper paint layer (glaze) of the background (Fig. 3) [7].

\section{Which materials did Vermeer use and where did they come from?}

The question of the geographic origin of the materials Vermeer used in Girl with a Pearl Earring can be answered by bringing together new findings about the composition of the painting, archival research (done in the 1990s [11]), and current knowledge about the trade 


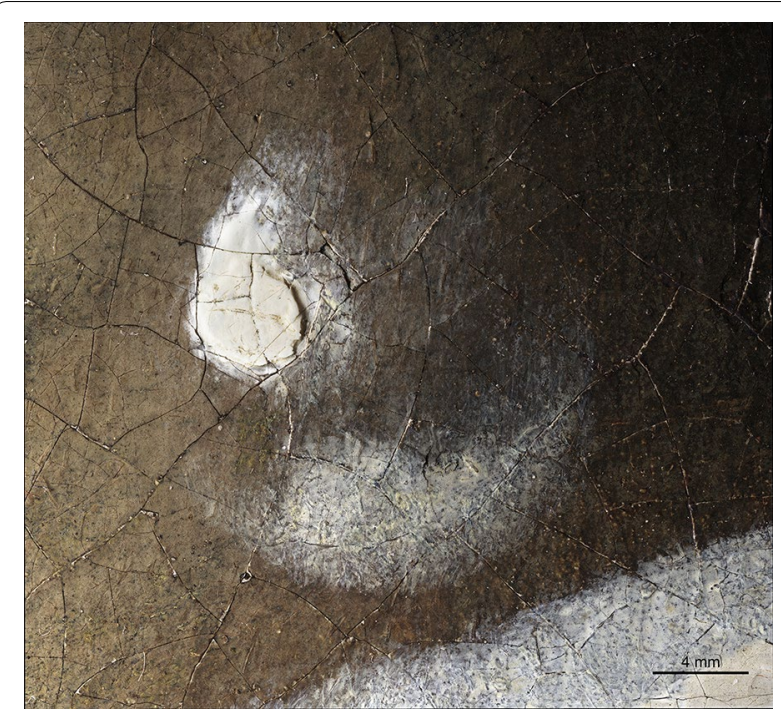

Fig. 2 Stitched 3D digital microphotograph $(\times 140,1.1 \mu \mathrm{m} /$ pixel) showing the pearl

of artists' materials $[12,13]$. The composition of the preparatory layers [3], pigments and binding medium of his paints [4, 7] was characterised as part of the Girl in the Spotlight project. The palette that Vermeer used in Girl with a Pearl Earring includes: reds (vermilion and red lake), yellows and browns (earth pigments, lead-tin yellow, yellow lake), blue (natural ultramarine and indigo), blacks (charcoal and bone black) and white (lead white) $[3-7,9]$. Before being processed into fine powders and sold by colourmen, apothecaries or grocers, these pigments originated from raw materials that came from different sources around the globe. Many of the pigments available to seventeenth-century painters were mined from the earth, then transported and traded; others were made synthetically using chemical processes $[12,13]$.

Vermeer used lead white to paint the Girl's collar, pearl earring and eyes, and he mixed it with other colours [4]. Recent lead isotope analysis determined that the lead ore used to make this pigment came from England [5]. Using the 'Dutch stack process' method, the raw material was turned into a useable pigment [14]. Remarkably, the pigment was further refined to produce at least two qualities or grades of lead white [5].

Vermeer also selected different types of black pigments, which resulted in subtly different colour effects or drying properties. Black pigments are made by charring plant matter or bones; they could easily have been produced locally. Charcoal was identified as the main component in the underlayer of the background of the Girl [7]. On top of this underlayer, he applied a green glaze containing yellow and blue colourants. Weld, a yellow dyestuff, is made from a plant (reseda luteola) that almost certainly grew in the Netherlands [2]. It was precipitated or adsorbed on an inert substrate (mainly chalk) to make it into a colourant. The source of the blue dye component in the background is more complicated. Most indigo identified in seventeenth-century paintings is derived from the plant Indigofera tinctoria L., which was usually imported from Asia, but also planted in the West Indies in the second half of the sixteenth century [15]. Another possible indigo source is Indigofera suffruticosa L., otherwise known as Guatemalan indigo. Indigo from the 'New World' was available in the Dutch republic in the seventeenth century and the transatlantic trade facilitated by

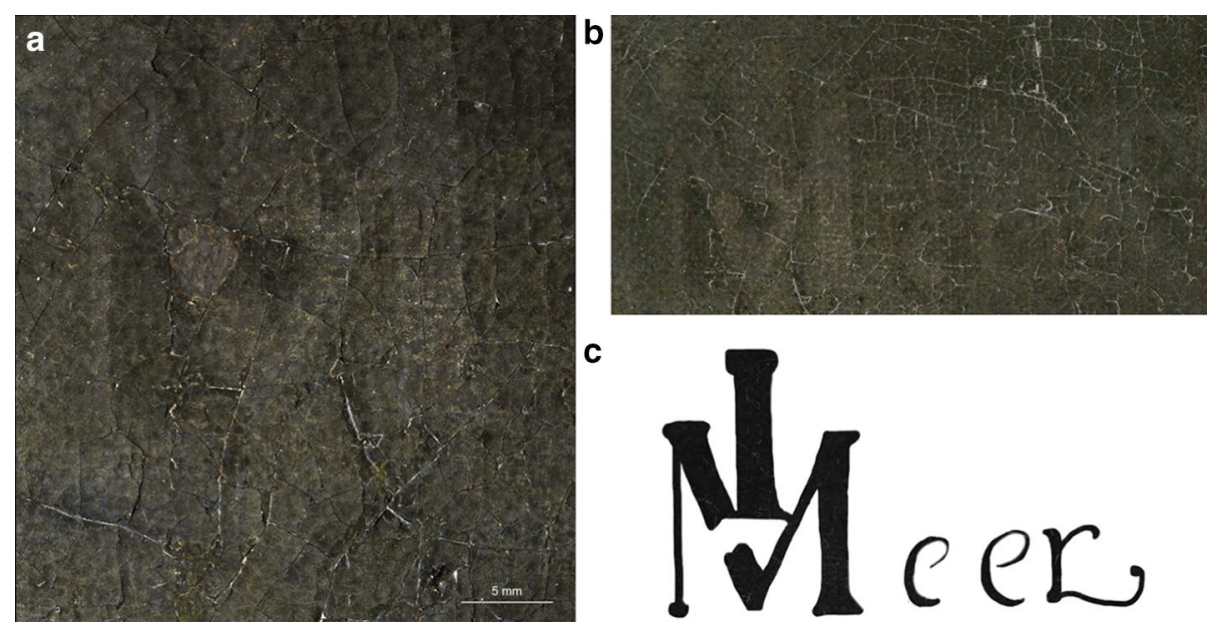

Fig. 3 a Stitched 3D digital microphotograph $(\times 140,1.1 \mu \mathrm{m} /$ pixel) showing the monogram in the signature. $\mathbf{b}$ Stitched 3D digital microphotograph $(35 \mathrm{x}, 4.4 \mu \mathrm{m} /$ pixel) showing the whole signature. c The signature, traced from MA-XRF elemental maps [7] 
the Dutch West India Company made it cheaper than indigo imported from Asia. Ship records from the 1670s mention imported indigo from the Americas [16]. For Girl with a Pearl Earring, the identification of the species and geographic origin remains speculative.

Another colourant that came from the other side of the globe is New World cochineal: otherwise known as Mexican or American cochineal. Insects that feed on prickly pear cacti were crushed to extract a red dyestuff, which had to be precipitated onto an inert substrate to be used as a colourant [14]. Cochineal was also used to dye wool and fabrics, so alternatively, the red dye could have been extracted from wool shearings [11, 14]. In Girl with a Pearl Earring, American cochineal (Dactylopius coccus Costa.) was identified in her clothing, but the precise source-extracted directly from the insect or from shearings-was not determined [6]. The other red pigment identified in her skin-vermilion-was almost certainly made synthetically within the Netherlands. In the seventeenth century, it was produced on a large scale, and Dutch vermilion was especially prized for its quality [14].

Lead-tin yellow was also made synthetically, and may have been abundantly available in Delft because it was used to colour glass and ceramics [14]. This pigment was identified in the border of the Girl's headscarf for the first time as part of this study (Fig. 4) [4]. In some shadows, Vermeer incorporated a yellow lake, which has since faded, but can be recognised by the remaining calcium from the substrate $[6,7]$. The other yellows and browns in the painting are made of earth pigments, which could have been sourced from one of many places in Europe. The bright yellow on the light side of the Girl's jacket is primarily composed of yellow ochre (Fig. 5) [4].

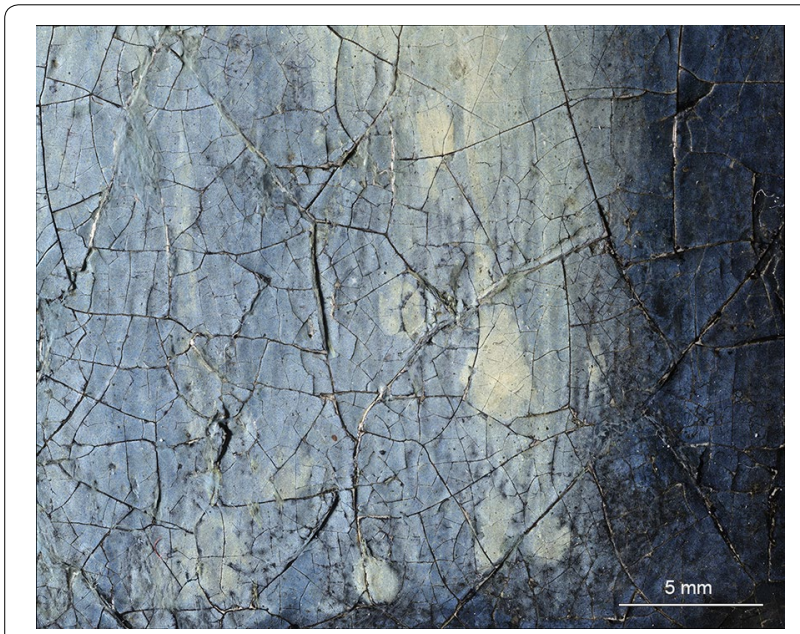

Fig. 4 Stitched 3D digital microphotograph $(\times 140,1.1 \mu \mathrm{m} /$ pixel) showing the border of the headscarf. The dots were painted with lead-tin yellow

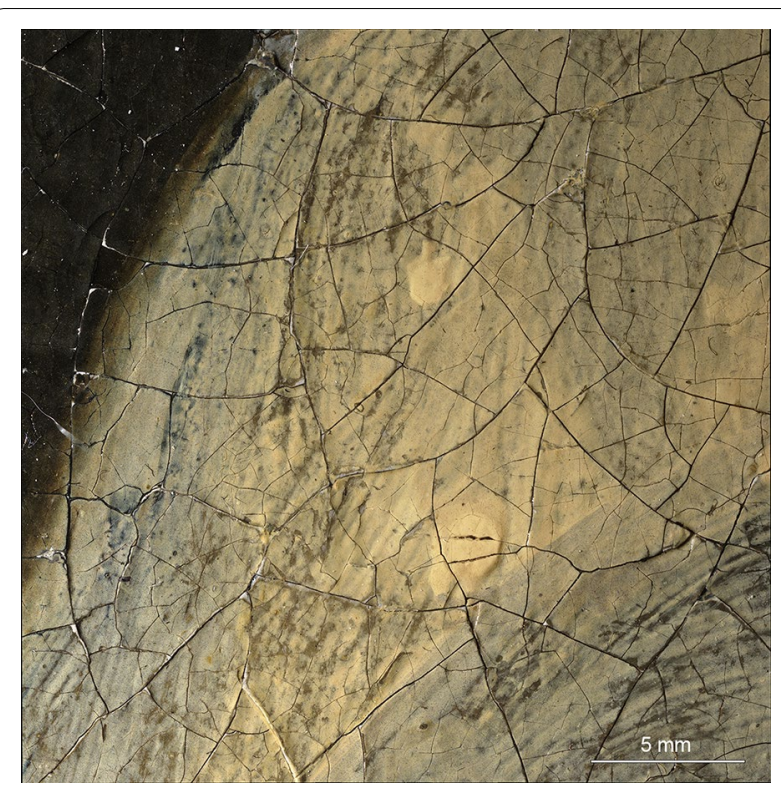

Fig. 5 Stitched 3D digital microphotograph $(\times 140,1.1 \mu \mathrm{m} /$ pixel) showing dots on the Girl's yellow jacket

Vermeer is remarkable in his abundant use of an expensive blue pigment: natural ultramarine [10]. In Girl with a Pearl Earring, he incorporated it liberally into her headscarf (Fig. 6), and also mixed into her jacket $[4,6]$. The lapis lazuli available in the seventeenth century came from a mountainous region in (what is now) Afghanistan. Some sources mention that the lapis lazuli rock was first heated before it was ground into a powder; this is most likely the case in Girl with a Pearl Earring [6]. The process to make high-quality ultramarine was laborious and

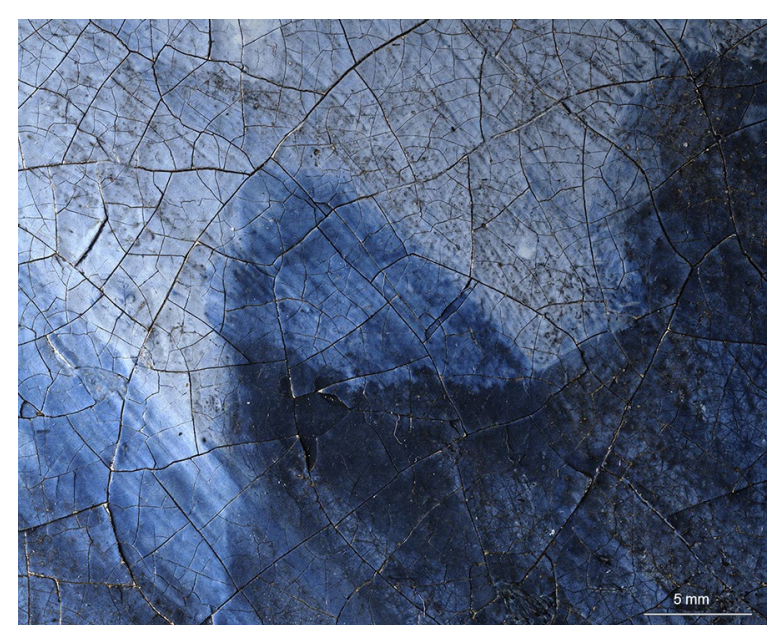

Fig. 6 Stitched 3D digital microphotograph ( $\times 140,1.1 \mu \mathrm{m} /$ pixel) showing overlapping layers in the blue headscarf 
time-intensive, and ultramarine of different grades and prices could be produced. The large particle size, colour intensity, and small amount of accessory minerals in the Girl's headscarf suggests that the ultramarine is of high quality [6].

Previous archival research showed that Vermeer could have purchased many of his materials locally, from apothecaries or grocers that specialised in painting materials [11]. Surprisingly, ultramarine was not among the lists of pigments in existing shop inventories [11]. Further refinement of specific pigments-for instance, obtaining different qualities of lead white using washing, heating or levigation-could have been done by specialist colourmen, or by artists themselves [5]. In Vermeer's studio, each colour of paint would be prepared by grinding the pigments in oil by using a muller on a slab of stone. In fact, a 1679 inventory of Vermeer's possessions made a few months after his death mentions that a stone table to grind colours on, along with the stone, were stored in his attic [17].

In 1994, chromatographic analyses of a sample from the background of the Girl found that the binding medium is linseed oil, which is typical of seventeenth-century Dutch paintings [2, 7]; however, recent chromatographic analysis revealed that a trace amount of rapeseed oil was also present [18]. Perhaps it is the result of contamination; in the seventeenth century, (wind) mills pressed oil from different sources, and the mill may not have been thoroughly cleaned between pressings. It also found that the oil used to paint the background was slightly heat-bodied, presumably to influence its rheological properties and make it settle into a smooth, glossy paint film [7].

Raw materials from around the world converged in the Netherlands as pigments and colourants, which eventually become incorporated into Girl with a Pearl Earring. With the exception of his abundant use of natural ultramarine, Vermeer's palette is rather typical for the seventeenth century. His innovation is demonstrated more clearly by the ways he mixed and layered his paints.

\section{Which techniques did Vermeer use to create subtle optical effects?}

By mixing different pigments, and/or layering different paints on top of each other, Vermeer achieved a wide range of colours with his palette. For example, the upper layers of paint in the Girl's jacket contain yellow ochre, surprisingly mixed with ultramarine, and incorporating lead white on the left (lit) side and red lake in the dark shadow [4]. He applied only one or two layers of paint in most areas. By varying the opacity and thickness of the upper layers, sometimes even leaving the underlayers (partially) exposed at the surface, he created subtle colour nuances (see question 1 above). The colour range was extended by applying translucent glazes on top of opaque underlayers. In the background, Vermeer layered a green glaze on top of a black underlayer to create a very dark green colour (which has since degraded: see question 5 below) $[2,7]$. One of the most surprising new findings is diagonal painted lines found in the upper right corner, and colour variations on the right side of the painting. These suggest that the backdrop was originally a green curtain $[2,7]$. On the left side of the painting, the dark background contrasts strongly with the Girl's face; however, Vermeer created a soft contour between them by leaving a gap between the two adjacent colour areas [3, $5,7]$ (see question 2 above). This gives the impression of light circulating around the side of her face [19].

Vermeer created the illusion of light falling on textured fabrics by applying clusters of small round dots. Blue dots dapple the surface of the headscarf, and yellow dots speckle the Girl's jacket [6, 8]. In the Girl's jacket, one protrudes about $50 \mu \mathrm{m}$ above the surrounding paint (Fig. 7). Microscopic examination showed that some dots overlap with each other: these double dots further enhance the three-dimensional effect (Fig. 7). Tiny double brushstrokes applied as highlights on the Girl's lips and eyes give the illusion of moisture and life (Figs. 8, 9). They contribute to the slightly blurry visual effect that has been associated with Vermeer's rendering of light. Some scholars have used the dots as an argument that Vermeer was inspired by-or worked directly from-the view through a camera obscura [20].

The dots enliven the surface of the painting and give the illusion of texture, but the exact type of material that is depicted remains unclear. Vermeer painted other parts of the composition-the left side of the Girl's nose, for example-with an astonishing vagueness, merely suggesting their form. In contrast, the eyes are more precise; her eyelashes were visualised for the first time as part of this study [5]. The smooth transitions of the skin in the Girl's face are the result of Vermeer's deliberate attempts to avoid sharp lines [18]. To create the imperceptible transition from light to shadow in the Girl's face, Vermeer probably used a soft dry brush to softly blend the (slightly) wet paint from light to shadow [5]. Microscopic examination found brush hairs embedded in the paint in these transitional areas [5, 21].

Vermeer manipulated the paint with different sized brushes at different stages of the painting process. In the beginning, he applied underlayers in her clothing with broad, rapid brushstrokes, as revealed in the infrared reflectograms [3]. For the background, he used vigorous strokes to apply the black underlayer, but as he approached the figure and the edges of the canvas, he worked more precisely, using smaller brushes and more careful strokes $[3,7]$. When Vermeer applied the upper 


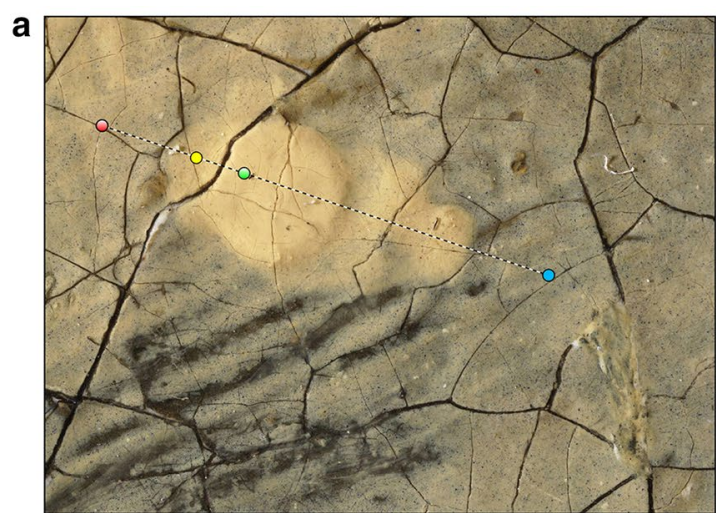

b

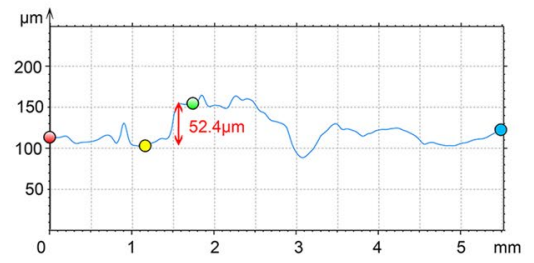

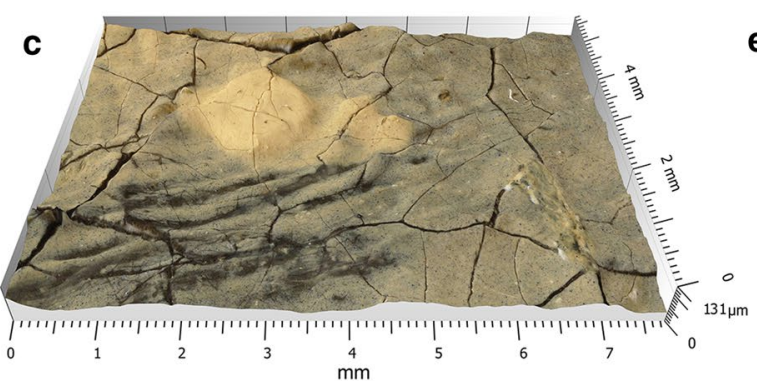

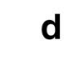

d

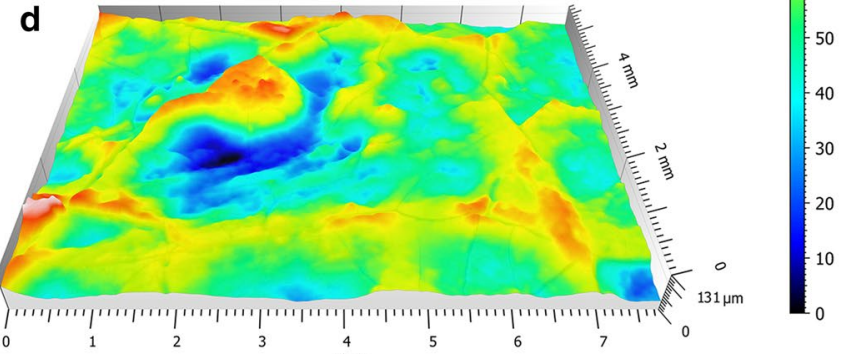

$\mathrm{mm}$

Fig. 7 a Stitched 3D digital microphotograph ( $\times 140,1.1 \mu \mathrm{m} /$ pixel) showing 'double dots' in the Girl's yellow jacket; the topographical profile shown in $\mathbf{b}$ is indicated with a line. In the lower left, the brown underlayer is visible where the yellow upper paint layer is thin. In the lower right is a retouching. $\mathbf{b}$ Topographical profile. Z-axis stretched $\times 10$ in relation to other axes. The height of the larger yellow dot is measured in relation to the surrounding paint. $\mathbf{c} 3 \mathrm{D}$ view of $\mathbf{a}$, tilted at $50^{\circ}$ beta viewing angle. Z-axis stretched $\times 4$ in relation to other axes. $\mathbf{d}$ Topographical map of $\mathbf{c}$. e Scale bar for d

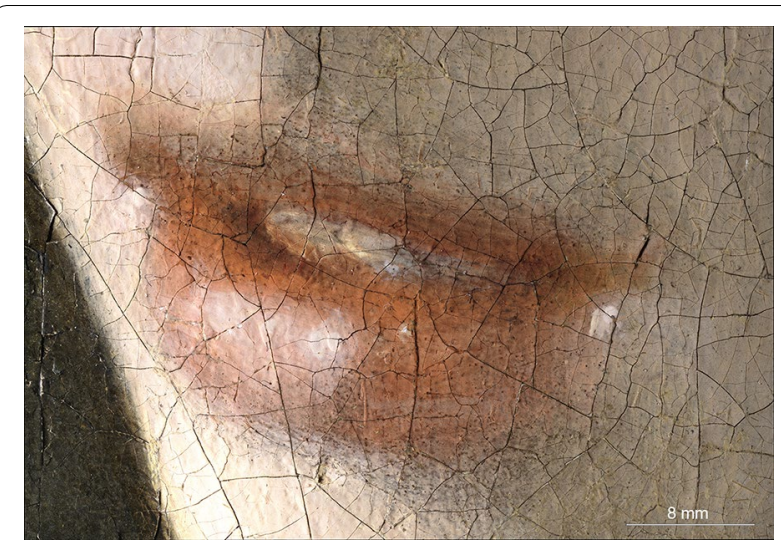

Fig. 8 Stitched 3D digital microphotograph $(\times 140,1.1 \mu \mathrm{m} /$ pixel) showing the Girl's lips paint layers, he used different brushes with varying widths. In the final stages, Vermeer used a fine brush loaded with paint to apply details, including the aforementioned dots and highlights.

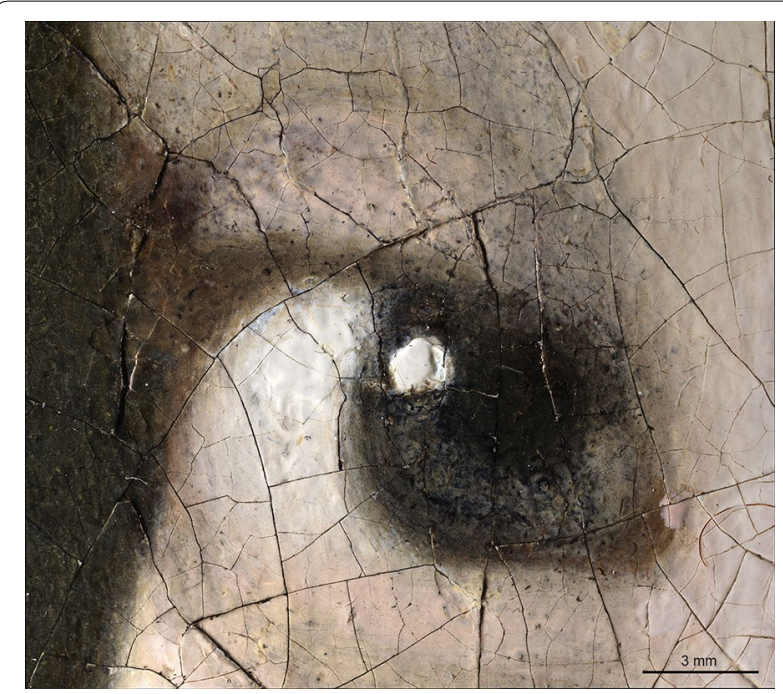

Fig. 9 Stitched 3D digital microphotograph $(\times 140,1.1 \mu \mathrm{m} /$ pixel) showing the left eye

Through these subtle effects, the viewer's gaze is directed to the parts that are in focus, creating a 
stronger and more intimate bond between the viewer and the Girl [19].

\section{What did the painting look like originally, and how has it changed?}

Preventive conservation measures are being taken at the Mauritshuis to preserve Girl with a Pearl Earring in as stable a condition as possible; however, it must be acknowledged that physical and chemical changes have occurred in the three-and-a-half centuries since it left Vermeer's studio. For example, the part of her headscarf in shadow has a particularly patchy and whitish appearance due to the presence of large amounts of chalk (probably as substrate of a-now faded-yellow lake) in the ultramarine-containing paint $[6,9]$. Degradation products have been identified within and at the surface of paint layers [9]. Amorphous areas within samples mounted as cross-sections show that lead-containing paints have undergone saponification, resulting in increased transparency [5]; the formation of lead soaps is a common deterioration mechanism observed in aged oil paintings. Some fugitive dyes have faded, but can be detected under specific conditions: for example, red lake incorporated into the shadow of the Girl's jacket is now barely visible to the naked eye, but luminesces in ultraviolet (UV)-induced fluorescence $[1,4]$. The presence of chalk in parts of her blue headscarf suggest that a yellow lake-now faded-may once have created greenish nuances in the shadow [6]. In the background, the organic components of the glaze-yellow weld and blue indigo-have both faded. The deterioration in the background has made Vermeer's signature difficult to discern (Figs. 3a, b); a visualisation of the signature was made by tracing the MA-XRF maps of calcium and lead (Fig. 3c) [7]. The deterioration in the background also masks the presence of diagonal 'folds' on the right side of the painting [7]. Although it now appears to be a flat backdrop, one of the most surprising new findings is that Vermeer painted diagonal painted lines in the upper right corner, and colour variations on the right side of the painting. These suggest that he originally intended the background to depict a green curtain behind the Girl [2, 7].

The 2018 Girl in the Spotlight examination chose to focus on Vermeer's original materials, but it is important to reflect on the conservation history to understand how Girl with a Pearl Earring survives in its current condition, both helped and hindered by the well-intended restoration treatments of the past $[1,2,17]$. It should be remembered that the authorship and importance of this painting had been forgotten prior to its 'rediscovery' as a work by Vermeer at the end of the nineteenth century [22]. It had suffered in harsh environmental conditions and developed a network of cracks, in some places exacerbated by restoration treatments in the early twentieth century [2, 8]. This explains, for example, why the impasto in several areas-most notably the pearl-was unfortunately flattened during historic linings (Fig. 2).

The imaging techniques used in the recent examination document the condition of the painting at this specific moment in time, and serve as a reference for changes that may occur in the future. They detected some of the restoration materials used in the past, including those used in the most recent (1994) treatment (Fig. 10) [2, 20, 23]. The topography of the painting was measured and visualised using several scientific techniques [8]. 3D scanning techniques, coupled with information about the deterioration of specific pigments, could lead to the development of 3D prints that approximate the appearance of both the surface colour and texture of Girl with a Pearl Earring when the painting left Vermeer's studio.

\section{Conclusion}

The Girl in the Spotlight technical examination was an object-focused study that aimed to reveal new insights about the materials and techniques that Vermeer used around the mid-1660s to bring Girl with a Pearl Earring to life. In the future, these findings can be considered within the context of Vermeer's oeuvre and paintings by other artists who worked in Delft [10].

Almost a quarter century elapsed between the Vermeer Illuminated (1994) and Girl in the Spotlight (2018)

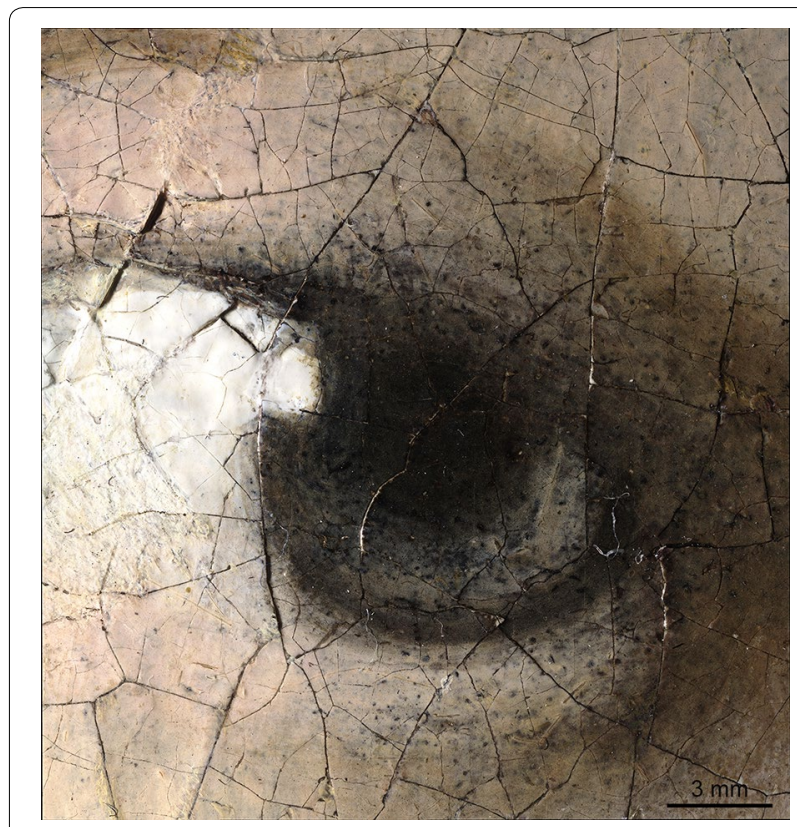

Fig. 10 Stitched 3D digital microphotograph $(\times 140,1.1 \mu \mathrm{m} /$ pixel $)$ showing the right eye. The paint covering cracks on the left side of the image is retouching 
projects [1]. Both were considered state-of-the-art at the time, but inevitably their outcomes were dependent on the advancement of knowledge and technologies being developed or adapted for the examination of artworks. One of the most important advances is the current suite of non-invasive technologies that map materials and their location throughout the bulk of the artwork; however, (micro)-invasive samples were still needed to fully comprehend the stratigraphy at specific points. The collective results from the different imaging techniques and the analysis of samples far exceeded the knowledge that could have been gained from each technique individually [1]. If we consider the future of technical examination projects and what they might offer 25 years from now, it is the combination and co-registration of data from new and different analytical techniques, and the way that they complement each other, that will provide the fullest understanding of an artwork.

Much like the geographic variety of materials that Vermeer used, the Girl in the Spotlight project was carried out by a multidisciplinary team of scientists and stateof-the-art equipment from around the world. The twoweek technical examination in front of the public allowed the team to share the first experience with visitors to the Mauritshuis. Readers of Heritage Science will have gained a more nuanced way of viewing and understanding the Girl and her making. Informed by the new findings from this examination and the ones that preceded it [2], the Girl in the Spotlight team hope that everyone can continue to look at Girl with a Pearl Earring with sheer enjoyment, and sense the intimacy Vermeer created between her and the beholder.

\section{Experimental methods}

All of the non-invasive imaging methods used during the Girl in the Spotlight project, and the analytical methods used to examine micro-samples, are listed in [1].

\section{High-resolution visible 3D digital microscopy}

The painting was examined using the Hirox RH-2000 3D digital microscope on a motorised 'bridge' stand with a $500 \times 500 \mathrm{~mm}$ automatic motorised $X Y$ stage $(200 \mathrm{~nm}$ steps). The 'bridge' stand was made specifically for the Girl in the Spotlight project to accommodate the painting, which was placed horizontally. The microscope zoom lens MXB-5000REZ was mounted on the Hirox FB-E $Z$-axis block with $30 \mathrm{~mm}$ motorised movement $(50 \mathrm{~nm}$ steps). It can achieve spatial sampling from $4.4 \mu \mathrm{m} /$ pixel $(35 \times)$ down to $0.03 \mu \mathrm{m} /$ pixel $(5000 \times)$, and for the figures in this article, $1.1 \mu \mathrm{m} /$ pixel $(140 \times$ magnification) with a tile size of $2.1 \times 1.31 \mathrm{~mm}$ was used. The illumination was mixed: raking light (100\% light intensity) and ring light/ dark field (10\% light intensity).
The microscope automatically acquired a series of images in the $Z$-axis, capturing each focus layer and then combining them in one single all-in-focus image (also known as $Z$-stacked or extended depth of field) as well as a TDR file (Hirox 3D file format), which includes true colours and altitude, so that the $X Y Z$ coordinates were registered for each pixel. The microscope then moved in the $X$ and/or $Y$ direction to the next tile. In addition to an automatic scan of the complete painting at $35 \times$ with $4.4 \mu \mathrm{m} / \mathrm{pixel}$, nine areas of interest were scanned at $140 \times$ $(1.1 \mu \mathrm{m} / \mathrm{pixel})$. The resulting high-resolution 3D stitching are displayed in an optimised web-based interface giving easy access to very high level of detail where individual pigment particles can be visualised and measured: www. micro-pano.com/pearl. The Hirox RH-2000 software with the 3D stitching option (modified specifically for this project) was used to calibrate, display and program a fully automatic $X Y Z$ acquisition with selectable overlap.

\section{Abbreviations}

3D: 3-dimensional; FIB-STEM: Focused ion beam—scanning transmission electron microscopy; FTIR-ATR: Fourier transform infrared-attenuated total reflectance spectroscopy; LIA: Lead isotope analysis; LM: Light microscopy; MA-XRPD: Macroscopic X-ray powder diffraction; MS-IRR: Multispectral infrared reflectography; SEM-EDX: Scanning electron microscopy-energy dispersive X-ray analysis; SIMS: Secondary ion mass spectrometry; THM-Py-GC/MS: Thermally assisted hydrolysis and methylation, pyrolysis gas chromatography-mass spectrometry; UHPLC-PDA-FLR: Ultra-high-performance liquid chromatography with a photodiode array, attached to a fluorescence detector; UV: Ultraviolet; $\mu$ XRPD: Micro-X-Ray powder diffraction; $\mu X A N E S$ : Micro-Xray absorption near edge structure.

\section{Acknowledgements}

The research project The Girl in the Spotlight is a Mauritshuis initiative, led by paintings conservator Abbie Vandivere, with a team of internationally recognised specialists working within the collaborative framework of the Netherlands Institute for Conservation + Art + Science + (NICAS), and scientists from the University of Antwerp, Belgium, and the National Gallery of Art, Washington DC, USA. The authors would also like to thank the following people for their comments and useful discussions in preparing this paper: Annelies van Loon, Sabrina Meloni, Carol Pottasch, Julianna Ly, Willemijn van Elkhuizen, Nicola Costaras, and the Girl in the Spotlight research team. Julianna Ly assisted with the tracing in Fig. 3c. Hirox would like to thank: Vincent Sabatier (Hirox Europe: Jyfel), Mr. Takamasa Takeuchi and Mr. Toshikazu Nakajima (Hirox Japan).

A special thanks to researchers from the Cultural Heritage Agency of the Netherlands (RCE): Art Ness Proaño Gaibor for finding the archival references to the indigo trade [16], and Henk van Keulen for performing thermally assisted hydrolysis and methylation, pyrolysis gas chromatography-mass spectrometry (THM-Py-GC-MS).

\section{NICAS partners}

Mauritshuis: Abbie Vandivere, Annelies van Loon; Rijksmuseum: Robert van Langh, Annelies van Loon, Alessa Gambardella (Rijksmuseum/AkzoNobel), Victor Gonzalez (Rijksmuseum/TU Delft), Robert Erdmann (Rijksmuseum/UvA); Cultural Heritage Agency of the Netherlands (RCE): Klaas Jan van den Berg, Bauke Zeilstra, Art Ness Proaño Gaibor, Suzan de Groot, Henk van Keulen; Delft University of Technology (TU Delft): Joris Dik, Tom Callewaert, Victor Gonzalez, Mathijs van Hengstum, Willemijn Elkhuizen, Tessa Essers, Yu Song, Jeroen Kalkman; University of Amsterdam (UvA): Robert Erdmann. 


\section{Other partners}

Shell Technology Centre Amsterdam (STCA): Bob van Wingerden, Ralph Haswell; National Gallery of Art, Washington DC: John Delaney, Kathryn A. Dooley; University of Antwerp: Koen Janssens, Geert van der Snickt, Steven De Meyer, Frederik Vanmeert, Rani Vertongen; Hirox Europe: Jyfel: Emilien Leonhardt, Vincent Sabatier/Hirox Japan: Mr. Takeuchi and Mr. Nakajima; Statens Museum for Kunst/CATS, Copenhagen: Jørgen Wadum; René Gerritsen Kunst \& Onderzoeksfotografie: René Gerritsen, Jaap Hoogerdijk, assistance with photographic set-up: Robert Erdmann; Maastricht University: Ron Heeren, Anne Bruinen, Hans Duimel; Vrije Universiteit Amsterdam/NICAS project: Multiisotopic analysis of early modern art (MITEEMA). Paolo D'Imporzano, Gareth R. Davies; European Synchrotron Radiation Facility (ESRF), Grenoble, France - ID21 beamline: Marine Cotte, Wout de Nolf; PETRA-III, Deutsches ElektronenSynchrotron (DESY), Hamburg, Germany - P06 beamline: Matthias Alfeld, Jan Garrevoet; 3D print displayed during Girl in the Spotlight examination: Océ: A Canon Company; Project team (Mauritshuis): Hedwig Wösten, Edwin Buijsen, Abbie Vandivere, Sandra Verdel, Boy van den Hoorn, Marty Plas, Julie Vegter.

\section{Authors' contributions}

AV wrote the main body of the text and was the Head Researcher for the Girl in the Spotlight project. JW discussed the content article, provided valuable feedback, and was one of the conservators who treated and researched the panting in 1994. EL carried out the examination with the Hirox 3D digital microscope, and provided the relevant images and experimental method. The Girl in the Spotlight research team had the opportunity to read and approve the final manuscript. All authors read and approved the final manuscript.

\section{Funding}

The Netherlands Institute for Conservation + Art + Science + funded the participation of the NICAS partners in the project, including use of analytical equipment and the time devoted to the project by scientists from the RCE, TU Delft, University of Amsterdam and the Rijksmuseum. The Girl in the Spotlight project was made possible with support from the Johan Maurits Compagnie Foundation.

\section{Availability of data and materials}

The datasets used and/or analysed during the current study are available from the corresponding author on reasonable request. The datasets supporting the conclusions of this article are included within the articles of this special issue of Heritage Science: [1, 3-9].

\section{Competing interests}

The authors declare that they have no competing interests.

\section{Author details}

${ }^{1}$ Conservation Department, Mauritshuis, Plein 29, 2511 CS The Hague, the Netherlands. ${ }^{2}$ CATS, Statens Museum for Kunst, Sølvgade 48-50, 1307 Copenhagen K, Denmark. ${ }^{3}$ Hirox Europe-Jyfel Corporation, 300 Route Nationale 6, Le bois des côtes, 69760 Limonest, France.

Received: 15 November 2019 Accepted: 30 January 2020 Published online: 02 March 2020

\section{References}

1. Vandivere A, Wadum J, van den Berg KJ, van Loon A. From 'Vermeer Illuminated' to 'The Girl in the Spotlight': approaches and methodologies for the scientific (re-)examination of Vermeer's Girl with a Pearl Earring. Herit Sci. 2019;7:66. https://doi.org/10.1186/s40494-019-0307-5.

2. Groen K, van der Werf I, van den Berg K, Boon J. Scientific examination of Vermeer's "Girl with a Pearl Earring". In: Gaskell I, Jonker M, editors. Vermeer Studies: Studies in the history of art 55. Washington, New Haven: National Gallery of Art, Yale University Press; 1988. p. 168-83.

3. Vandivere A, van Loon A, Dooley KA, Haswell R, Erdmann RG, Leonhardt E, Delaney JK. Revealing the painterly technique beneath the surface of Vermeer's Girl with a Pearl Earring using macro- and microscale imaging. Herit Sci. 2019;7:64. https://doi.org/10.1186/s40494-019-0308-4.

4. Delaney JK, Dooley KA, Van Loon A, Vandivere A. Mapping the pigment distribution of Vermeer's Girl with a Pearl Earring. Herit Sci. 2020;8:4. https:// doi.org/10.1186/s40494-019-0348-9.
5. Van Loon A, Vandivere A, Delaney J, Dooley K, De Meyer S, Vanmeert F, Janssens K, Gonzalez V, Leonhardt E, Haswell R, de Groot S, Proaño Gaibor AN, D'Imporzano P, Davies GR. Beauty is skin deep: the skin tones of Vermeer's Girl with a Pearl Earring. Herit Sci. 2019;7:102. https://doi.org/10.1186/s4049 4-019-0344-0.

6. Van Loon A, Vandivere A, Gambardella A, Gonzalez V, Keune K, Haswell R, de Groot S, Proaño Gaibor AN, Leonhardt E, Dooley K, Delaney J. Out of the blue: Vermeer's use of ultramarine in Girl with a Pearl Earring. Herit Sci. 2020. https://doi.org/10.1186/s40494-020-00364-5.

7. Vandivere A, van Loon A, Callewaert T, Haswell R, Proaño Gaibor AN, van Keulen $\mathrm{H}$, Leonhardt E, Dik J. Fading into the background: the dark space surrounding Vermeer's Girl with a Pearl Earring. Herit Sci. 2019;7:69. https:// doi.org/10.1186/s40494-019-0311-9.

8. Elkhuizen WS, Callewaert TWJ, Leonhardt E, Vandivere A, Song Y, Pont SC, Geraedts JMP, Dik J. Comparison of three 3D imaging techniques for paintings, as applied to Vermeer's Girl with a Pearl Earring. Herit Sci. 2019;7:89. https://doi.org/10.1186/s40494-019-0331-5.

9. De Meyer S, Vanmeert F, Vertongen R, van Loon A, Gonzalez V, Dik J, Van der Snickt G, Vandivere A, Janssens K. Imaging secondary reaction products at the surface of Vermeer's Girl with the Pearl Earring by means of in situ macro X-ray powder diffraction scanning. Herit Sci. 2019;7:67. https://doi. org/10.1186/s40494-019-0309-3.

10. Costaras N. A study of the materials and techniques of Johannes Vermeer. In: Gaskell I, Jonker M, editors. Vermeer studies: studies in the history of art 55. New Haven, National Gallery of Art: Washington; 1998. p. 145-67.

11. Levy-van Halm K. Where did Vermeer buy his painting materials? Theory and practice. In: Gaskell I, Jonker M, editors. Vermeer studies: studies in the history of art 55. New Haven, National Gallery of Art:Washington; 1998. p. 137-43.

12. Kirby J, Nash S, Cannon J, editors. Trade in artists' materials: markets and commerce in Europe to 1700. London: Archetype Publications Ltd.; 2010.

13. Haack Christensen A, Jager A. Trading paintings and painters' materials 1550-1800. CATS proceedings IV. London: Archetype Publications Ltd; 2019.

14. Harley RD. Artists' pigments C. 1600-1835: a study in English documentary sources. Reprint of 2 edition. London: Archetype Publications Ltd.; 2001.

15. EikemaHommes $M$, Appendix A. Indigo as a pigment in oil painting and its fading: tropical indigo plants. Changing pictures: discoloration in 15th-17th-century oil paintings. London: Archetype Publications Ltd; 2004. p. 215-7.

16. Spangien. Oprechte Haerlemsche courant. Haerlem, 19-02-1667. Delpher. https://resolver.kb.nl/resolve?urn=ddd:010926740:mpeg21:a0007. Accessed 27 May 2019.

17. Van Peer AJJM. Drie collecties schilderijen van Jan Vermeer. Oud Holland. 1957; 72. p. 92-103. https://www.jstor.org/stable/42718101.

18. Van Keulen H. Slow-drying oil additives in modern oil paints and their application in conservation treatments: an analytical study in technical historical perspective. In: Bridgland J, editor. ICOM-CC 17th Triennial Conference Preprints, Melbourne, 15-19 September 2014. Paris: International Council of Museums; 2014. art. 1316, p. 8.

19. Wadum J. Contours of Vermeer. In: Gaskell I, Jonker M, editors. Vermeer Stud ies: studies in the history of art 55. New Haven and London, National Gallery of Art: Washington DC; Yale University Press; 1998. p. 201-23.

20. Janson J. Vermeer and the camera obscura. In: Essential Vermeer 3.0. 2001-19. http://www.essentialvermeer.com/camera_obscura/co_one.html. Accessed 01 Oct 2019.

21. Wadum J, Hoppenbrouwers R, Struick van der Loeff L. Vermeer illuminated. Conservation, restoration and research. Wormer: $V+K$ Publishing/Inmerc, Amsterdam; 1994

22. Broos B. Vermeer: malice and misconception. In: Gaskell I, Jonker M, editors. Vermeer Studies: studies in the history of art 55. New Haven and London, National Gallery of Art: Yale University Press; 1988. p. 19-33.

23. Wadum J, Costaras N. Johannes Vermeer's 'Girl with a Pearl Earring'De- \& Re-Restored. In: Restauration, Dé-Restauration, Re-Restauration, Preprints of ARAAFU's 4th International Symposium; 1995 Oct 5-7; Paris.

\section{Publisher's Note}

Springer Nature remains neutral with regard to jurisdictional claims in published maps and institutional affiliations. 